\title{
Benthic Diversity of Sessile Organisms in Rocky Reef Habitats of Coastal Brazil: An Insight into the Implementation of Marine Protected Areas
}

\author{
Ralf Riedel*, Fernando Castro-Cardoso, Gabriel Correal, Mauricio Mata Jr. \\ Project Grouper, ATEVI, Ilhabela, Brazil \\ Email: ^ralf.riedel@usm.edu
}

How to cite this paper: Riedel, R., Castro-Cardoso, F., Correal, G. and Mata Jr., M. (2018) Benthic Diversity of Sessile Organisms in Rocky Reef Habitats of Coastal Brazil: An Insight into the Implementation of Marine Protected Areas. Natural Resources, 9, 404-412.

https://doi.org/10.4236/nr.2018.912025

Received: November 26, 2018

Accepted: December 21, 2018

Published: December 24, 2018

Copyright $\odot 2018$ by authors and Scientific Research Publishing Inc. This work is licensed under the Creative Commons Attribution International License (CC BY 4.0).

http://creativecommons.org/licenses/by/4.0/

cC) (i) Open Access

\begin{abstract}
Marine Protected Areas are increasingly becoming a tool of choice for conservation and management of marine resources and ecosystems. Data on biodiversity are necessary to assist in establishing protected areas for conservation objectives to be met. Toward that effect, we investigated reef biodiversity patterns in three large-scale coastal regions of Brazil. The study areas comprised of an upwelling region, an adjacent high impacted region, and a more distant marine park. We surveyed four reef sites in each study region. Species counts of sessile benthic organisms, substrate relief, and average monthly water temperatures were recorded during the surveys. Benthic organisms were identified to the lowest taxa possible using still photos. Biodiversity was estimated using Shannon's index on richness of organism taxa. Diversity was highest at the upwelling and high-impacted areas. No substrate relief patterns were found. Temperature readings showed lower average values at the upwelling and high impacted regions. Our results favor the upwelling region for establishment of a Marine Protected Area. Moreover, the similar diversity between the upwelling and the high impacted regions showed evidence of spillover effects from the former into the latter region, further demonstrating the importance of the former region for conservation.
\end{abstract}

\section{Keywords}

Conservation, Marine Protected Areas, Biodiversity, Reefs, Benthic, Brazil, Coastal Habitat

\section{Introduction}

Shallow reef ecosystems are increasingly becoming degraded from human activities, coastal development, and commercial activities. As human population 
grows and expands to coastal areas, threats to reef habitats will continue unabated. Additionally, many human activities increase the likelihood of environmental contamination through introduction of invasive species, further threatening the stability of coastal ecosystems [1]. To curb this trend, reef habitat conservation and recovery efforts need to employ proven techniques toward that goal, of which protected areas are likely the most promising.

Marine protected areas have proven effective in conservation of several ecosystems, including reef habitats [2] [3] [4]. Its widespread adoption by local, national, and international regulators attests to its effectiveness in conservation and recovery of coastal habitats for commercially important or emblematic species [5]. The benefits of MPAs in the conservation of non-target species and the maintenance of ecosystem functions are, however, still not well known [6]. For such techniques to be effective siting is one of the most important factors to consider [7] [8]. Locations of MPAs need to include a network of high diversity sites to provide optimum viability to the persistence of such networks long term [9]. Toward objective, we investigate three areas in terms of diversity of non-target benthic biota to assist in marine conservation policies and recovery efforts of coastal ecosystems.

\section{Materials and Methods}

Research of benthic diversity was conducted in shallow reef habitats of the Rio de Janeiro and São Paulo states. The study regions comprised of an upwelling area to the north, an adjacent high impacted area, and a more distant marine park to the south (Figure 1). At each region, four sites were chosen and two depths strata at each site. Depth strata were less than $8 \mathrm{~m}$ and between 10 and 15 $\mathrm{m}$. At each depth strata, two $20 \mathrm{~m}$ long transects were randomly selected for investigations. Each depth stratum was visited once every quarter from December 2013 to June 2015, totaling six data collection visits.

Data collections for biodiversity were done by SCUBA using quadrats $25 \mathrm{~cm}$ on a side. Twenty quadrats were placed randomly along each transect before a still digital photograph of each was taken. Photographs were processed to extract percent area covered by benthic organism. Organisms were identified to the lowest taxa possible during photograph processing. No live organisms were taken, to minimize habitat disturbance during data collection events. Data collection for substrate relief were conducted using a $5 \mathrm{~m}$ chain placed at random locations in each stratum. The chain was draped over rocks and boulders and the loss of length recorded (no relief implies in a stretched-out chain, i.e., no loss of the $5 \mathrm{~m}$ chain length). Loss of length was used as the estimate of substrate complexity. Water temperature data was obtained by placing one continuous temperature logger at each study region.

Data analysis comprised of estimates of biodiversity, substrate relief, and water temperature patterns for the study area. Estimates were obtained using independent analysis of variance (AOV) factorial designs. The Shannon index of 


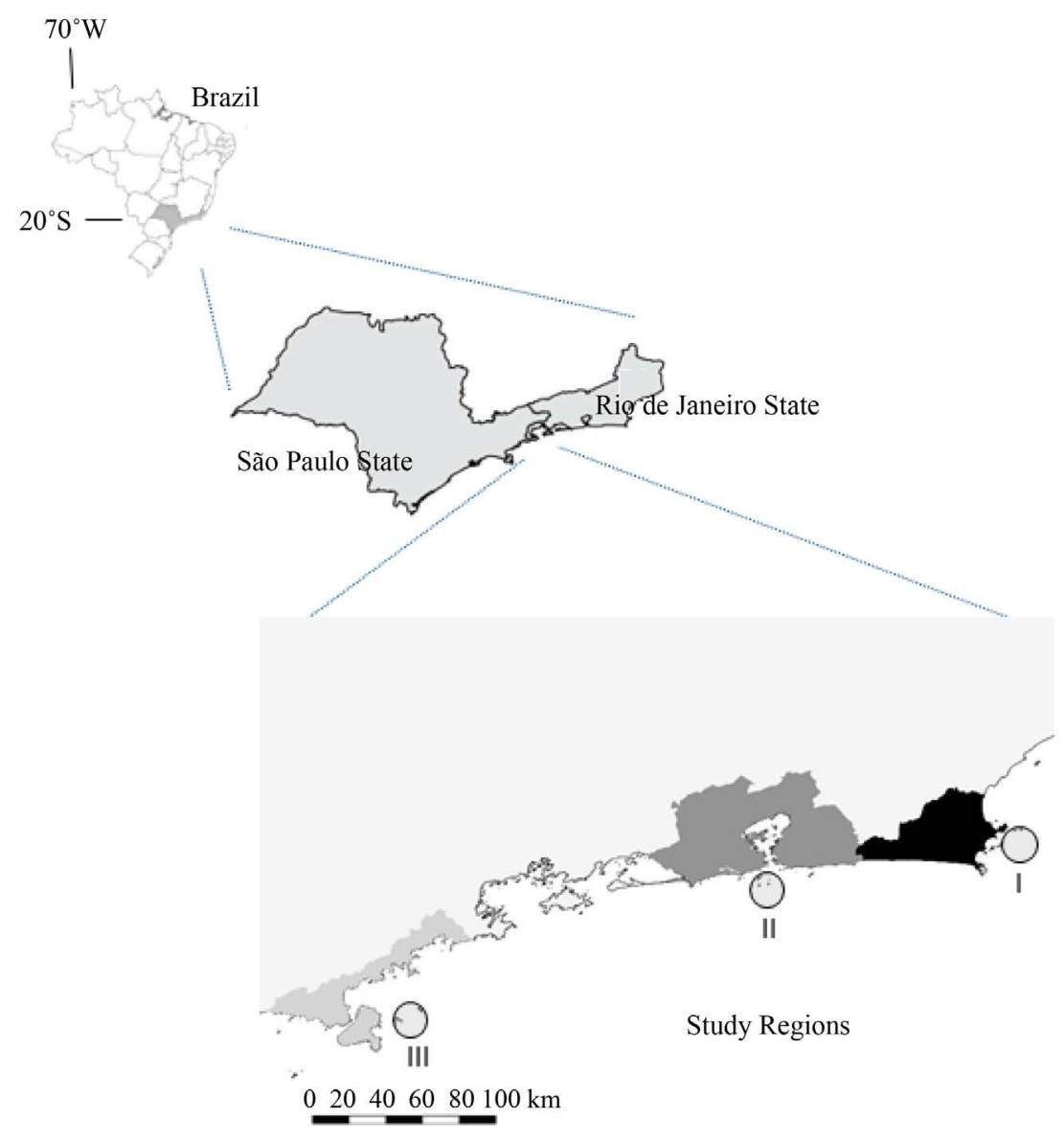

Figure 1. Study area and regions I-III (in circles) used in benthic biodiversity studies along the coast of Rio de Janeiro and São Paulo states, Brazil; Region I: upwelling area, Region II: high-impact area, Region III: marine park.

biodiversity was the response variable for the biodiversity analysis. Average monthly temperature was the response for water temperature pattern estimates. Loss of chain length was the response for the substrate complexity analyses. Region and stratum were the factors selected for AOV analyses. Sites were not included as factors because they had no ecological relevance aside from serving as replicates within study regions.

To avoid biases for biodiversity analyses, only organisms identified to genus or species were included in analyses. In case an organism was only possible to be identified to genus and it was the only species observed throughout the study, it was included in analyses and assigned a species denomination (sp.).

\section{Results and Discussion}

Fifty-one organisms were sampled at all regions combined (Table 1). The vast majority of the observations were of macroalgae, echinoderms, and poriphera, typical of shallow-water marine ecosystems. The region with most organisms was the upwelling region, followed by the high-impact region, with the marine park last. The shallow stratum always yielded the most organisms (Table 2), 
Table 1. List of organisms identified and total counts during biodiversity studies at shallow-water reef habitats on the coasts of São Paulo and Rio de Janeiro states, Brazil; Region I: upwelling area, Region II: high-impact area, Region III: marine park.

\begin{tabular}{|c|c|c|c|c|}
\hline Taxa & Region I & Region II & Region III & Total Count \\
\hline Dictyota sp. & 384 & 342 & 184 & 915 \\
\hline Echinometra locunter & 266 & 211 & 78 & 555 \\
\hline Jania adhaerens & 287 & 161 & 94 & 542 \\
\hline Tedania ignis & 136 & 199 & 183 & 518 \\
\hline Sargassum vulgare & 120 & 202 & 168 & 490 \\
\hline Neogoniolithon sp. & 144 & 176 & 125 & 445 \\
\hline Colpomenia sinuosa & 232 & 106 & 100 & 438 \\
\hline Aplysinia fulva & 85 & 115 & 67 & 267 \\
\hline Darwinella sp. & 65 & 112 & 49 & 226 \\
\hline Myllepora alcicornis & 160 & 0 & 17 & 177 \\
\hline Padina gymnospora & 102 & 18 & 29 & 149 \\
\hline Mussismilia hispida & 53 & 3 & 90 & 146 \\
\hline Tubastrea sp. & 38 & 1 & 103 & 142 \\
\hline Arbacea lixula & 16 & 117 & 4 & 137 \\
\hline Pachychalina alcaloidifera & 29 & 35 & 58 & 122 \\
\hline Plocamium brasiliense & 17 & 67 & 22 & 106 \\
\hline Botrylloides nigrum & 26 & 27 & 32 & 85 \\
\hline Dideminum sp. & 23 & 42 & 18 & 83 \\
\hline Aliclona vansaeste & 24 & 37 & 16 & 77 \\
\hline Siderastrea stellata & 74 & 0 & 1 & 75 \\
\hline Palythoa caribaeorum & 3 & 0 & 62 & 65 \\
\hline Mycale angulosa & 12 & 37 & 6 & 55 \\
\hline Macrorhynchia philipina & 3 & 16 & 31 & 50 \\
\hline Dyctioptera sp. & 26 & 9 & 13 & 48 \\
\hline Phallusia nigra & 9 & 3 & 35 & 47 \\
\hline Lytechinus variegatus & 2 & 39 & 4 & 45 \\
\hline Asteronema breviarticulatum & 15 & 3 & 13 & 31 \\
\hline Mananchora arbuscula & 3 & 21 & 3 & 27 \\
\hline Dysidea etheria & 2 & 20 & 3 & 25 \\
\hline Phyllogorgia dilatata & 23 & 0 & 1 & 24 \\
\hline Schizoporella unicornis & 1 & 17 & 4 & 22 \\
\hline Carijoa riisei & 0 & 2 & 17 & 19 \\
\hline Bunodosoma caissarum & 1 & 18 & 0 & 19 \\
\hline Echinaster brasiliensis & 3 & 2 & 9 & 14 \\
\hline Monastrea cavernosa & 1 & 0 & 9 & 10 \\
\hline Isostichopus badionotus & 3 & 4 & 0 & 7 \\
\hline Amphimedon viridis & 7 & 0 & 0 & 7 \\
\hline Lophogorgia sp. & 0 & 2 & 5 & 7 \\
\hline
\end{tabular}




\begin{tabular}{cllll}
\hline Arenosclera brasiliensis & 6 & 0 & 0 & 6 \\
Madracis decactis & 6 & 0 & 0 & 6 \\
Hypselodoris lajensis & 5 & 0 & 0 & 5 \\
Hypselodoris picta & 0 & 3 & 0 & 3 \\
Callisponjae pseudotoxa & 0 & 2 & 1 & 3 \\
Hemimycale sp. & 0 & 0 & 2 & 2 \\
Cirripedia sp. & 1 & 1 & 0 & 2 \\
Nascissia trigonaria & 1 & 0 & 0 & 1 \\
Holothuria sp. & 0 & 1 & 0 & 1 \\
Gymnothorax moringa & 0 & 0 & 1 & 1 \\
Astropecten sp. & 0 & 0 & 1 & 1 \\
\hline
\end{tabular}

Table 2. Mean species count by study region and depth stratum observed during biodiversity studies at shallow-water reef habitats on the coasts of São Paulo and Rio de Janeiro states, Brazil.

\begin{tabular}{ccccc}
\hline Region & Stratum & N & Mean & Std \\
\hline Upwelling & Shallow & 48 & 8.50 & 2.79 \\
Upwelling & Deep & 48 & 5.65 & 2.93 \\
High-Impact & Shallow & 48 & 8.48 & 2.67 \\
High-Impact & Deep & 48 & 6.27 & 2.55 \\
Marine Park & Shallow & 43 & 8.26 & 3.25 \\
Marine Park & Deep & 42 & 4.07 & 2.22 \\
\hline
\end{tabular}

which is also expected, due to its higher exposure to sunlight.

The highest diversity was found in the upwelling and the adjacent high-impact regions, with no statistical difference between both. The marine park had the lowest diversity among all three regions (Figure 2). This may at first be counter-intuitive, since the high-impacted region is located in a metropolitan area, with detrimental impacts from human recreation, such as diving and spear-fishing, and pollution. As the high-impact area is south from the upwelling area, there may, however, be a strong overspill from the upwelling area into the high-impacted area, supplying the latter with biological resources. The major driver of the observed overspill effects may be the predominantly north-south current flow at the study region [10]. Overspill effects are often reported one of the many benefits of marine protected areas, as they do not only preserve habitat and resources locally, but may be a source for open, adjacent areas [11] [12] [13] [14].

The shallow stratum consistently had a higher diversity compared with the deep stratum (Figure 2). Unlike the results above by region, this is expected. The shallow stratum was generally around $5 \mathrm{~m}$ deep, compared with the deep stratum of around $12 \mathrm{~m}$ deep. Near coastal waters at the study area are rich in planktonic and non-skeletal suspensates, which impedes light from penetrating 


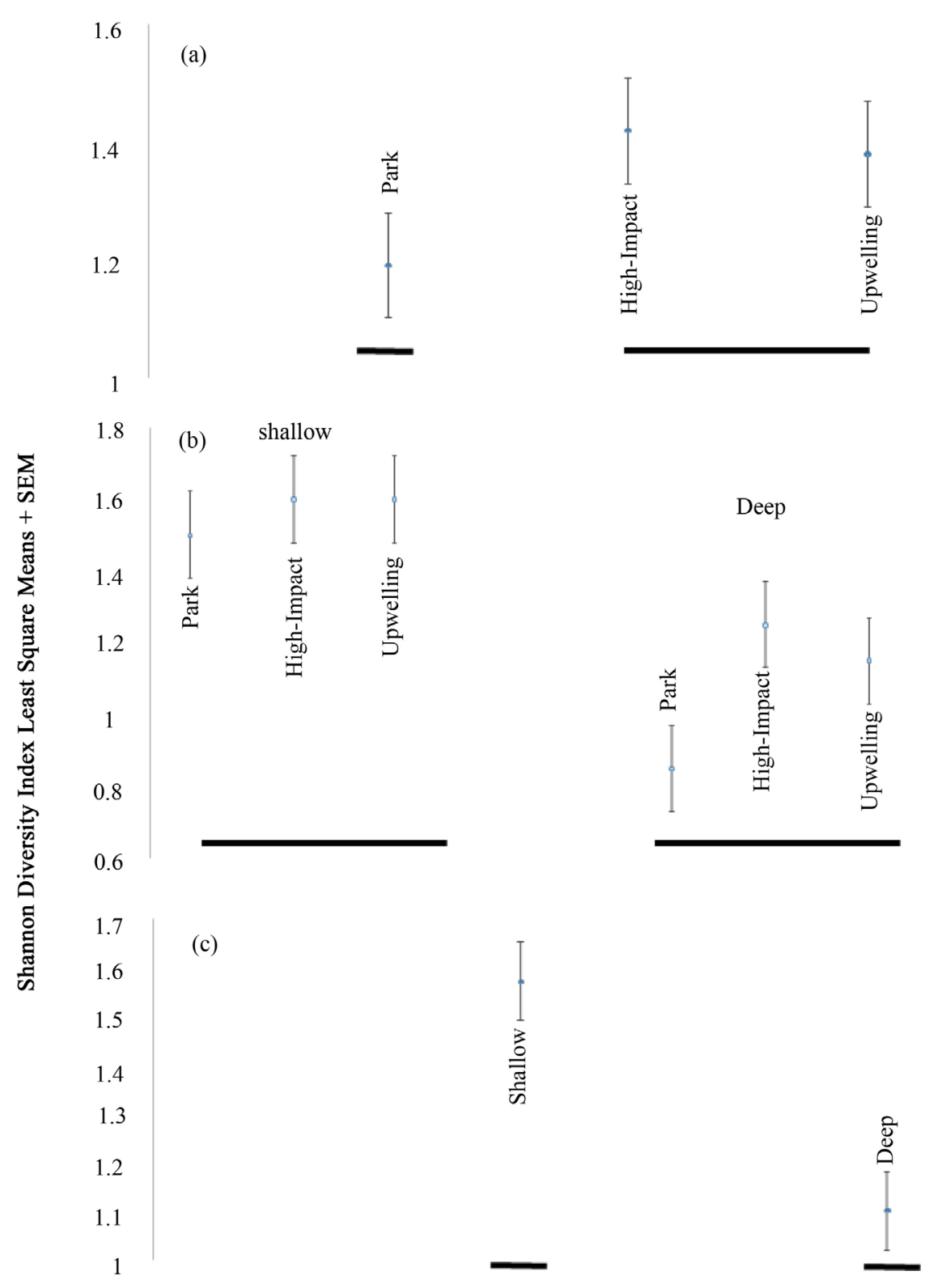

Figure 2. Analysis of variance least square means \pm standard error of Shannon biodiversity indices following biodiversity studies on the coasts of São Paulo and Rio de Janeiro states, Brazil; panel (a): factor Region, panel (b): factor Region X Stratum; panel (c): factor Stratum; lines indicate factor grouping significance (continuous lines under factor indicate non-significance).

higher depths [15]. What could be surprising is the rate of diversity losses with depth, placing a higher importance of shallow reef habitats in the maintenance of biodiversity.

The mechanisms driving the diversity patterns in the study area were not clear from the results obtained herein. Habitat complexity as indicated by chain length losses seems not to have been a factor driving diversity patterns, as no statistically significant differences were found in substrate relief among regions or depth stratum. Habitat complexity is known to affect diversity of aquatic ha- 
bitats [16] [17] [18], indicating that for this study other factors were at play in determining the observed biodiversity patterns.

One of such factors could be associated with water temperature, as there was a statistically significant difference of monthly average water temperature among region and between depth strata (Figure 3). Water temperature per se, however,

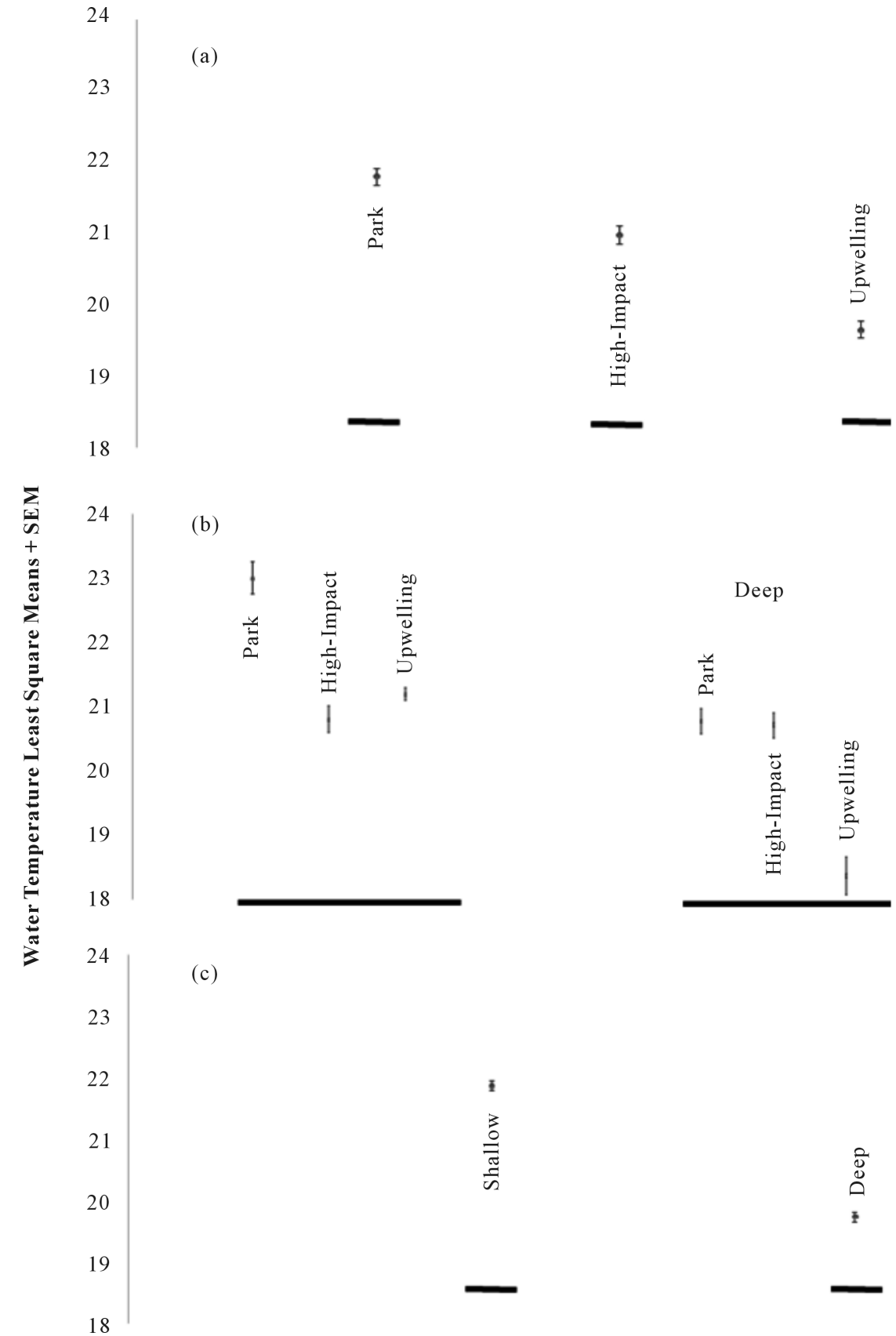

Figure 3. Analysis of variance least square means \pm standard error of water temperature following biodiversity studies on the coasts of São Paulo and Rio de Janeiro states, Brazil; panel A: factor Region, panel B: factor Region X Stratum; panel C: factor Stratum; lines indicate factor grouping significance (continuous lines under factor indicate non-significance). 
was likely not the driving factor, as biodiversity patterns did not parallel that of temperature. Water temperature was lowest for the deep stratum (low diversity) and highest at the marine park (low diversity). We, therefore, conclude that water temperature is an indicator of upwelling phenomena, serving as a surrogate variable to indicate such regions at our study area. Other factors, possibly more related to nutrient availability from upwelling currents, are possibly at play for determining the observed biodiversity patterns.

\section{Conclusion}

The implementation of protected areas has great promise for recovering degraded habitats and preservation of entire ecosystems. Siting of such areas, however, is of prime importance in determining the effectiveness of such conservation practices. Setting aside areas of great diversity may be preferable, as they constitute more effective sources for adjacent, open areas. There is, however, a trade-off, as high-diversity areas are also prime locations for recreation or commercial fishing activities [12] [14]. We demonstrated in this study that high-diversity areas may benefit adjacent areas of high human impact. As the importance of intact ecosystems becomes more apparent, trade-offs between preservation and economic interests may increasingly tip toward preserving ecosystems, especially if the benefits of spillover effects are demonstrated, as done in this study.

\section{Acknowledgements}

Financial support for this project provided in full by the program Petrobras Socioambiental, Petrobras, Brazil. We also recognize and thank the Ecological Station Tamoios for their continued logistical and technical support throughout this project and Dr. Guilherme Muricy, from the Federal University of Rio de Janeiro National Museum, for his assistance in identification of benthic organisms.

\section{References}

[1] Kaplan, K., Hart, D., Hopkins, K., Gallager, S., York, A., Taylor, R. and Sullivan, P. (2017) Invasive Tunicate Restructures Invertebrate Community on Fishing Grounds and a Large Protected Area on Georges Bank. Biological Invasions, 20, 87-103. https://doi.org/10.1007/s10530-017-1517-y

[2] Ban, N., Davies, T., Aguilera, S., Brooks, C., Cox, M., Epstein, G., Evans, L., Maxwell, S. and Nenadovic, M. (2017) Social and Ecological Effectiveness of Large Marine Protected Areas. Global Environmental Change, 43, 82-91. https://doi.org/10.1016/j.gloenvcha.2017.01.003

[3] Friedlander, A., Golbuu, Y., Ballesteros, E., Caselle, J., Gouezo, M., Olsudong, D. and Sala, E. (2017) Size, Age, and Habitat Determine Effectivenss of Palau's Marine Protected Areas. PLOS ONE, 12, e0174787. https://doi.org/10.1371/journal.pone.0174787

[4] Welch, H., Pressey, R. and Reside, A. (2018) Using Temporally Explicit Habitat Suitability Models to Assess Threats to Mobile Species and Evaluate the Effective- 
ness of Marine Protected Areas. Journal of Nature Conservation, 41, 106-115. https://doi.org/10.1016/j.jnc.2017.12.003

[5] Nicoll, R. and Day, J. (2017) Correct Application of the IUCN Protected Area Management Categories to the CCAMLR Convention Area. Marine Policy, 77, 9-12. https://doi.org/10.1016/j.marpol.2016.11.035

[6] Mellin, C., MacNeil, M., Cheal, A., Emslie, M. and Caley, M. (2016) Marine Protected Areas Increase Resilience among Coral Reef Communities. Ecology Letters, 19, 626-637. https://doi.org/10.1111/ele.12598

[7] Cabral, R., Gaines, S., Lim, M., Atrigenio, M., Mamauag, S., Pedemonte, G. and Alino, P. (2017) Siting Marine Protected Areas Based on Habitat Quality and Extent Provides the Greatest Benefit to Spatially Structured Metapopulations. Ecosphere, 7, e01533. https://doi.org/10.1002/ecs2.1533

[8] Cox, C., Valdivia, A., McField, M., Castillo, K. and Bruno, J. (2017) Establishment of Marine Protected Areas Alone Does Not Restore Coral Reef Communities in Belize. Marine Ecology Progress Series, 563, 65-79. https://doi.org/10.3354/meps11984

[9] Visconti, P. and Elkin, C. (2009) Using Connectivity Metrics in Conservation planning-When Does Habitat Quality Matter? Diversity and Distributions, 15, 602-612. https://doi.org/10.1111/j.1472-4642.2009.00564.x

[10] Lima, I., Garcia, C. and Moller, O. (1996) Ocean Surface Processes on the Southern Brazilian Shelf: Characterization and Seasonal Variability. Continental Shelf Research, 16, 1307-1317. https://doi.org/10.1016/0278-4343(95)00066-6

[11] Andrello, M., Mouillot, D., Somot, S., Thuiller, W. and Manel, S. (2014) Additive Effects of Climate Change on Connectivity between Marine Protected Areas and Larval Supply to Fishes Areas. Diversity and Distributions, 21, 139-150. https://doi.org/10.1111/ddi.12250

[12] Colleter, M., Gascuel, D., Albouy, C., Francour, P., Morais, L., Valls, A. and Le Loch, F. (2014) Fishing Inside or Outside? A Case Study Analysis of Potential Spillover Effect from Marine Protected Areas Using Food-Web Models. Journal of Marine Systems, 139, 383-395. https://doi.org/10.1016/j.jmarsys.2014.07.023

[13] Di Lorenzo, M., Claudet, J. and Guidetti, P. (2016) Spillover from Marine Protected Areas to Adjacent Fisheries Has an Ecological and Fishery Component. Journal for Nature Conservation, 32, 62-66. https://doi.org/10.1016/j.jnc.2016.04.004

[14] Cuervo-Sanchez, R., Madonado, J. and Rueda, M. (2018) Spillover from Marine Protected Areas on the Pacific Coast in Colombia: A Bioeconomic Modeling Approach for Shrimp Fisheries. Marine Policy, 88, 182-188. https://doi.org/10.1016/j.marpol.2017.10.036

[15] Summerhayes, C., Melo, U. and Barretto, H. (1976) The Influence of Upwelling on Suspended Matter and Shelf Sediments Off Southeastern Brazil. Journal of Sedimentary Research, 46, 819-828.

[16] Ding, B., Curole, J., Husemann, M. and Danley, P. (2014) Habitat Complexity Predicts the Community Diversity of Rock-Dwelling Cichlid Fish in Lake Malawi, East Africa. Hydrobiologia, 748, 133-143. https://doi.org/10.1007/s10750-014-1932-3

[17] Oyugi, D., Mavuti, K., Aloo, P., Ojuok, J. and Britton, J. (2014) Fish Habitat Suitability and Community Structure in the Equatorial Lake Naivasha, Kenya. Hydrobiologia, 727, 51-63. https://doi.org/10.1007/s10750-013-1785-1

[18] Martelo, J., Grossman, G., Porto, M. and Magalhaes, M. (2014) Habitat Patchiness Affects Distribution and Microhabitat Use of Endangered Mira Chub Squaliustorgalensis (Actimopterygii, Cypriniformes). Hydrobiologia, 732, 93-109. https://doi.org/10.1007/s10750-014-1850-4 